\title{
Toxoplasmose em ovinos e caprinos: estudo soroepidemiológico em duas regiões do Estado de Pernambuco, Brasil
}

\author{
Sheep and goat toxoplasmosis: soroepidemiological \\ study in two regions in the State of Pernambuco, Brazil

\begin{abstract}
Aristeu Vieira da Silva ${ }^{1}$ Eva Laurice Pereira Cunha ${ }^{2}$ Luciana R.Meireles $^{2}$ Susana Gottschalk ${ }^{2}$ Rinaldo Aparecido Mota $^{3}$ Helio Langoni ${ }^{4}$
\end{abstract}

\section{RESUMO}

Com o objetivo de comparar variáveis epidemiológicas na toxoplasmose em ovinos e caprinos, amostras de soro de animais de propriedades localizadas em duas regiões do Estado de Pernambuco, Brasil, foram testadas pela reação de imunofluorescência indireta (RIFI) para detecção de anticorpos anti-Toxoplasma gondii. Dos 173 soros ovinos testados, em 35,3\% foram encontrados resultados positivos, enquanto 40,4\% dos 213 soros caprinos foram positivos à RIFI. Em ovinos, associações significativas foram encontradas para sexo e raça, mas não para região, tipo de manejo ou falha reprodutiva. Os resultados da RIFI para os caprinos foram significativamente associados ao sexo, raça, região, tipo de manejo e de exploração, mas não com a ocorrência de falhas reprodutivas.

Palavras-chave: toxoplasmose, ovinos, caprinos, RIFI, epidemiologia.

\section{ABSTRACT}

In order to compare some epidemiological variables in goat and sheep toxoplasmosis, serum samples of animals from different farms in two regions from the State of
Pernambuco, Brazil, were tested by indirect fluorescent antibody test (IFAT). Of 173 sheep sera tested, $35.3 \%$ had positive results, while $40.4 \%$ of 213 goats serum samples were positive to IFAT. In sheep, significant associations were found to sex and breed, but not to region, kind of management or reproductive failure. Results of IFAT for goats were associated to sex, breed, region, kind of management and exploration, but not to reproductive failure.

Key words: toxoplasmosis; sheep; goat; IFAT; epidemiology.

\section{INTRODUÇÃO}

O Toxoplasma gondii é um protozoário de ciclo de vida facultativamente heteroxeno e infecta todas as espécies de animais homeotérmicos, incluindo mamíferos, aves e o homem. É prevalente em muitas áreas do mundo, tendo importância veterinária e médica, por ser causa de aborto e doença congênita em várias espécies de hospedeiros intermediários (TENTER et al., 2000).

\footnotetext{
${ }^{1}$ Médico Veterinário, Mestre em Vigilância Sanitária, Núcleo de Pesquisas em Zoonoses (NUPEZO), Departamento de Higiene Veterinária e Saúde Pública (DHVSP), Faculdade de Medicina Veterinária e Zootecnia (FMVZ), Universidade Estadual Paulista (UNESP), Distrito de Rubião Jr, s/n, Botucatu, SP, Brazil, CEP 18.618-000. Endereço para correspondência: FMVZ/UNESP/Botucatu - Distrito de Rubião Jr., s/n, CEP 18.618-000, Botucatu, SP. fone (14) 68220240, silva.av@uol.com.br ${ }^{2}$ Médicos Veterinários, NUPEZO, DHVSP, FMVZ, UNESP, Botucatu.

${ }^{3}$ Médico Veterinário, Professor Adjunto, Departamento de Medicina Veterinária, Universidade Federal Rural de Pernambuco.

${ }^{4}$ Médico Veterinário, Professor Adjunto, NUPEZO, DHVSP, FMVZ, UNESP, Botucatu.
} 
Desde 1954, o parasita é descrito como agente de abortamentos na espécie ovina, sendo considerado a maior causa de problemas reprodutivos nesta espécie(UNDERWOOD \& ROOK, 1992). Estudo conduzido no Uruguai apontou a toxoplasmose como problema importante nos rebanhos ovinos, promovendo prejuízos anuais de US\$ 1,4 a 4,7 milhões (FREYRE et al., 1999). MUNDAY \& MASON (1979) foram os primeiros a descreverem a toxoplasmose como importante causa de prejuízos reprodutivos em caprinos, e apesar de menos documentada nesta espécie, aparentemente os danos são maiores, acometendo clinicamente também animais adultos (DUBEY, 1987). Para as duas espécies, a principal via de infecção é a ingestão de oocistos esporulados do parasita(DUBEY \& BEVERLEY, 1988).

As taxas de infecção apontadas para rebanhos caprinos e ovinos no Brasil são variáveis, e este comportamento deve-se principalmente ao teste sorológico utilizado, à região e idade dos animais estudados (DUBEY, 1990). LARSSON et al. (1980) encontraram $39,0 \%$ de positivade em ovinos abatidos no Rio Grande do Sul. Em Minas Gerais, MACHADO \& LIMA (1987) apontam 36,8\% de caprinos positivos em 46 propriedades estudadas, com taxa de $36,1 \%$ entre os rebanhos leiteiros e 11,4\% nos animais de corte. GONDIM et al. (1999) encontraram 18,75\% e 28,93\% de ovinos e caprinos, respectivamente, positivos ao teste de aglutinação ao látex, em pesquisa realizada na Bahia.

LANGONI et al. (1999), pesquisaram anticorpos anti-Toxoplasma em 352 amostras de soros de ovinos de 18 propriedades do Estado de São Paulo, pelas provas de imunofluorescência indireta (RIFI) e hemaglutinação indireta (HAI). A RIFI revelou 55,1\% de amostras reagentes enquanto na HAI somente $30,4 \%$ foram positivas, o que reforça a importância da padronização das técnicas sorológicas utilizadas no diagnóstico desta infecção.

SPOSITO-FILHA et al. (1992) isolaram 20 cepas de toxoplasma a partir do diafragma de 100 ovinos. DA SILVA \& LANGONI (2001) isolaram o parasita do cérebro e diafragma de 34 dos 40 ovinos sorologicamente reagentes à imunofluorescência indireta. Estes trabalhos de isolamento de parasitas viáveis de tecidos comestíveis, bem como de leite caprino (CHIARI \& NEVES, 1984) revelam a importância destas espécies como fonte de infecção para o homem.

O presente trabalho teve como objetivo verificar a frequência de caprinos e ovinos positivos pela a reação de imunofluorescência indireta para a detecção de anticorpos séricos anti-T.gondii, bem como verificar a associação destes resultados com variáveis epidemiológicas em rebanhos provenientes de duas regiões geográficas do Estado de Pernambuco, Brasil.

\section{MATERIALEMÉTODOS}

Amostras de sangue foram coletadas de 173 ovinos (10 propriedades) e 213 caprinos (10 propriedades) de propriedades localizadas em duas regiões geográficas do Estado de Pernambuco, região nordeste do Brasil. A região da Zona da Mata está próxima ao mar, com alto índice pluviométrico no inverno e clima ameno durante todo o ano, e o Agreste é uma zona de transição entre o litoral e o interior do Estado, de clima mais seco e menores índices pluviométricos. Cinco das propriedades de criação de ovinos e caprinos estavam localizadas na Zona da Mata, e as outras na região do Agreste. Em cada propriedade $10 \%$ dos animais com mais de um ano de idade foram aleatoriamente amostrados, e os proprietários entrevistados para obtenção de dados referentes a sexo, raça, manejo, tipo de exploração e ocorrência de distúrbios reprodutivos. Os dados epidemiológicos e as amostras de sangue foram colhidas entre junho e julho de 1997. O soro obtido por centrifugação do sangue a $1600 \mathrm{~g}$ por 10 minutos foi aliquotado e estocado a $-20^{\circ} \mathrm{C}$ até o processamento do exame laboratorial.

A presença de anticorpos anti-T.gondii foi determinada pela reação de imunofluorescência indireta (RIFI), segundo CAMARGO (1974). Anticorpo antiIgG-caprina e anti-IgG-ovina conjugado à fluoresceina foi fornecido pelo Centro de Controle de Zoonoses da Prefeitura Municipal de São Paulo, São Paulo, Brasil. Diluições do soro na razão quatro, de 1:16 a 1:4096, foram testadas e reações à diluição 1:16 ou maior foram consideradas positivas.

Os dados epidemiológicos foram armazenados e analisados utilizando-se o programa EpiInfo 6.04c. A análise estatística foi realizada tendo cada animal como uma unidade de análise, e os fatores associados com os resultados do teste sorológico foram identificados por tabelas de associação para valores independentes, considerando-se $\alpha=0,05$.

\section{RESULTADOS E DISCUSSÃO}

A tabela 1 resume as distribuições de sexo, raças, manejo, tipo de exploração e perdas reprodutivas nas vinte propriedades estudadas. Um total de 61 $(35,30 \%)$ de 173 soros ovinos e $86(40,40 \%)$ de 213 soros caprinos reagiram com títulos $\geq 16$ (Tabela 2), e esta diferença de taxa de infecção entre as espécies também é apontada por GARCIA-VÁZQUEZ et al. (1990) e GONDIM et al. (1999). Das dez propriedades de ovinos amostradas, nove tinham animais com reações positivas, com $14,90 \%$ a $90,90 \%$ de soropositividade em cada propriedade. Todas as pro- 
Tabela 1 - Comparação das variáveis sexo, raça, manejo, exploração e perdas reprodutivas, em rebanhos ovinos e caprinos de duas regiões do Estado de Pernambuco, Brasil.

\begin{tabular}{|c|c|c|c|c|}
\hline \multirow[b]{2}{*}{ Variáveis } & \multicolumn{2}{|c|}{ Ovinos } & \multicolumn{2}{|c|}{ Caprinos } \\
\hline & $\mathbf{N}$ & (\%) & $\mathbf{N}$ & $(\%)$ \\
\hline \multicolumn{5}{|l|}{ Sexo } \\
\hline Machos & 38 & $(22,0)$ & 33 & $(15,5)$ \\
\hline Fêmeas & 135 & $(78,0)$ & 180 & $(84.5)$ \\
\hline \multicolumn{5}{|l|}{ Raça } \\
\hline Mista & 126 & $(72,8)$ & 109 & $(51,2)$ \\
\hline Pura* & 47 & $(27,1)$ & 104 & $(48,8)$ \\
\hline \multicolumn{5}{|l|}{ Região } \\
\hline Agreste & 56 & $(32,4)$ & 111 & $(52,1)$ \\
\hline Zona da Mata & 117 & $(67,6)$ & 102 & $(47,9)$ \\
\hline \multicolumn{5}{|l|}{ Manejo } \\
\hline Extensivo & 98 & $(56,6)$ & 88 & $(41,3)$ \\
\hline Intensivo & 75 & $(43,4)$ & 125 & $(58,6)$ \\
\hline \multicolumn{5}{|l|}{ Exploração } \\
\hline Leiteira & 0 & $(0,0)$ & 111 & $(52,1)$ \\
\hline Corte & 173 & $(100,0)$ & 102 & $(47,9)$ \\
\hline \multicolumn{5}{|c|}{ Perdas reprodutivas** } \\
\hline Presentes & 37 & $(21,4)$ & 105 & $(49,3)$ \\
\hline Ausentes & 136 & $(78,6)$ & 108 & $(50,7)$ \\
\hline
\end{tabular}

* Raças puras de ovinos: Santa Inês ( $\mathrm{n}=30 ; 17.3 \%$ ) e Suffolk ( $\mathrm{n}=17 ; 9.8 \%$ ); Raças puras de caprinos: Saanen ( $\mathrm{n}=66 ; 31.0 \%)$, Tonnenburg, $\mathrm{n}=16$; $7.5 \%)$, Pardo Suiça $(\mathrm{n}=11 ; 5.2 \%)$ e Alpina $(\mathrm{n}=11 ; 5.2 \%)$

** Infertilidade foi relatada em ovinos e o aborto em caprinos

priedades de caprinos apresentavam animais positivos, com soropositividade entre $15,90 \%$ a $87,50 \%$. A tabela 3 apresenta a associação das variáveis epidemiológicas com o resultado da RIFI, nos animais amostrados, considerando-se nível de significância de $5 \%$.

Para caprinos, a porcentagem de fêmeas soro-reagentes foi significativamente maior $(\mathrm{OR}=2,91)$ que a de machos, com $43,88 \%$ contra $21,21 \%$, respectivamente, com $\chi^{2}=5,05$ e $p<0,05$. Já as amostras de ovinos apresentaram comportamento contrário, com maior porcentagem de reagentes $(\mathrm{OR}=2,21)$ entre os machos $\left(50,00 \% \times 31,11 \% ; \chi^{2}=3,84 ; p<0,05\right)$. Este comportamento díspar pode se dever à interação entre variáveis, por exemplo o manejo dos animais, já que a concentração de fêmeas caprinas em manejo intensivo para exploração leiteira, poderia influenciar no resultado da comparação entre o sexo e soro-reação. No entanto o mesmo não pode ser verificado para a espécie ovina.
Maiores taxas de infecção em animais mestiços foram encontradas nas duas espécies, com $51,92 \%$ e $40,48 \%$ de reagentes entre os caprinos $\left(\chi^{2}=10,34\right.$; $\mathrm{OR}=2,60)$ e ovinos $\left(\chi^{2}=4,72\right.$; OR=2,52), respectivamente, resultados estatisticamente significativos, podendo este comportamento ser devido ao menor cuidado no manejo higiênico-sanitário das criações de animais mestiços. GARCIA-VÁZQUEZ et al. (1990) apontam diferença de prevalência de infecção pelo T.gondii entre ovinos das raças Pelibuey (47,00\%) e Rambouillet (20,00\%), mas não discutem as possíveis causas deste achado.

A maior prevalência de infecção em regiões úmidas, verificada neste trabalho, em caprinos originários da região da Zona da Mata $\left(51,96 \% ; \chi^{2}=10,01\right.$; $\mathrm{OR}=2,56$ ), é relatada também por GONDIM et al. (1999) em regiões geográficas com condições climáticas semelhantes às deste trabalho. Neste caso, a umidade e o tipo de vegetação contribuem para a formação de um 
Tabela 2 - Recíproca dos títulos de anticorpos anti-T.gondii à RIFI, segundo o sexo, em soros de ovinos e caprinos de duas regiões do Estado de Pernambuco, Brasil.

\begin{tabular}{|c|c|c|c|c|c|c|c|c|}
\hline & & & & & Título & & & \\
\hline Espécie & Sexo & Negativo & $16(\%)$ & $64(\%)$ & $256(\%)$ & $1024(\%)$ & $4096(\%)$ & Total (\%) \\
\hline \multirow[t]{2}{*}{ Ovino } & Macho & $19(50,0 \%)$ & $13(34,2 \%)$ & $0(0 \%)$ & $6(15,8 \%)$ & $0(0 \%)$ & $0(0 \%)$ & $38(21,9 \%)$ \\
\hline & Fêmea & $93(68,9 \%)$ & $35(25,9 \%)$ & $1(0,7 \%)$ & $5(3,7 \%)$ & $1(0,7 \%)$ & $0(0 \%)$ & $135(78,1 \%)$ \\
\hline \multirow[t]{2}{*}{ Caprino } & Macho & $26(78,8 \%)$ & $3(9,1 \%)$ & $0(0 \%)$ & $4(12,1 \%)$ & $0(0 \%)$ & $0(0 \%)$ & $33(15,5 \%)$ \\
\hline & Fêmea & $101(56,1 \%)$ & $61(33,9 \%)$ & $5(2,8 \%)$ & $11(6,1 \%)$ & $1(0,6 \%)$ & $1(0,6 \%)$ & $180(84,5 \%)$ \\
\hline
\end{tabular}

microambiente mais favorável à manutenção de oocistos viáveis no solo, que são as principais formas de transmissão para os herbívoros. Entretanto, ao contrário do relatado por GONDIM et al. (1999), não foi verificada diferença significativa $\left(\chi^{2}=2,08 ; \mathrm{OR}=1,77\right)$ nas taxas de infecção de ovinos criados no Agreste (26,78\% de sororeações) e na Zona da Mata (39,32\% de soro-reações), o que pode se dever à interação com o tipo de manejo dos animais, onde também não houve diferença significativa $\left(\chi^{2}=0,11 ; \mathrm{OR}=1,17\right)$.

As criações de cabras, com manejo intensivo, bem como as propriedades leiteiras $(54,05 \%$ de soro-reagentes; $\mathrm{OR}=3,43$ ) apresentaram prevalência significativamente maior de infecção pelo Toxoplasma, com $52,80 \%$ de animais reagentes $\left(\chi^{2}=18,17 ; \mathrm{OR}=3,80\right)$. MACHADO \& LIMA (1987) e OPEL et al. (1991) apontaram maior prevalência do T.gondii em caprinos de propriedades de exploração leiteira, discutindo que, nestas criações, a maior concentração dos animais, associada à oferta de alimento contaminado favorece a transmissão e infecção dos animais. Por outro lado, em criações de caprinos para corte, normalmente extensivas, o pastejo alto, de folhas e ramos, e a aversão dos caprinos por áreas úmidas diminui a chance de infecção (MACHADO \& LIMA, 1997), como pode ser verificado em nosso trabalho, com taxas de infecção de $25,49 \%$ dos animais criados para fins de abate. A despeito de não se verificar diferença $\left(\chi^{2}=0,11 ; \mathrm{OR}=1,17\right)$, neste trabalho, entre os resultados de tipo de criação para a espécie ovina, WALTNER-TOEWS et al. (1991), CRUZ-VAZQUES et al. (1992) e MAINAR et al. (1996) apontam maior risco de infecção em animais criados confinados, devido a maior exposição destes à fonte de infecção, especialmente quando há a presença de um gato excretor. Durante a coleta de dados para este trabalho, não foi avaliada a presença de outros animais nas propriedades. Com isso, não foi possível verificar a associação desta variável com os resultados do exame sorológico.

Tanto para caprinos como para ovinos, não foi encontrada associação significativa entre a ocor- rência de problemas reprodutivos e a soro-reação ao T.gondii, inclusive com porcentagens de soro-reação menores nos grupos em que as perdas reprodutivas foram relatadas, com $15,62 \%$ de sororeagentes entre os ovinos $\left(\chi^{2}=3,79 ; \mathrm{OR}=3,03\right)$ e $37,96 \%$ entre os caprinos $\left(\chi^{2}=1,20 ; \mathrm{OR}=0,69\right)$. A ausência de associações significativas para esta variável, apesar de contrastar com os dados da literatura mundial, que apontam a toxoplasmose como a principal causa de aborto de pequenos ruminantes (UNDERWOOD \& ROOK, 1992), pode dever-se a natureza dos dados colhidos, já que não houve, para nenhuma das espécies, um estudo mais aprofundado da causa de infertilidade. Assim, seria muito interessante a realização de pesquisas aprofundadas nestas populações, com acompanhamento sorológico rotineiro, verificando-se as taxas de soroconversão e a associação com os distúrbios reprodutivos, obtenção de amostras de soro pareadas e mesmo o exame de fetos abortados, visando o isolamento ou a detecção do T.gondii, seja por técnicas imunológicas, bioensaios ou biologia molecular.

A região nordeste do Brasil, área de grande concentração de criações de ovinos e caprinos, tem alterado seu sistema de produção, de criações extensivas que ocupam grandes áreas, para criações intensivas, com grande concentração de animais, próximas a centros urbanos, onde a difusão de enfermidades infecciosas é facilitada pelo contato com outras espécies e pelo manejo intenso dos animais. Neste contexto, o estudo da toxoplasmose entre estes animais é relevante, devido à potencial ocorrência de problemas da esfera reprodutiva e a possibilidade de transmissão do agente para o homem, seja pela carne ou pelo leite de animais infectados no caso dos caprinos.

\section{REFERÊNCIASBIBLIOGRÁFICAS}

CAMARGO, M.E. Introdução às técnicas de imunofluorescência. Revista Brasileira de Patologia Clínica, São Paulo, n.1, v.10, p.143-169,1974. 
CHIARI, C.A.; NEVES, D.P. Toxoplasmose humana adquirida através da ingestão de leite de cabra. Memórias do Instituto Oswaldo Cruz, Rio de Janeiro, n.3, v.79, p.337-340, 1984.

CRUZ-VAZQUEZ, C. et al. Ovine toxoplasmosis in Huitzilac, Morelos, anf the polymerase chain reaction (PCR). Veterinary Parasitology, Amsterdam, n.3, v.97, p.191-198, 2001.

DA SILVA, A.V.; LANGONI, H. The detection of Toxoplasma gondii by comparing citology, histopathology, bioassay in mice, and the polymerase chain reaction (PCR). Veterinary Parasitology, Amsterdam, v.97, n.3, p.191-198, 2001.

DUBEY, J.P. Status of toxoplasmosis in sheep and goats in the United States. Journal of The American Veterinary Medical Association, Schaumburg, n.2, v.196, p.259-262, 1990.

DUBEY, J.P. Toxoplasmosis in goats. Agri-practice, New York, n.3, v.8, p.43-52, 1987

DUBEY, J.P.; BEVERLEY, J.K.A. Toxoplasmosis of animals and man. Boca Ráton: Academic, 1988. 315p.

FREYRE, A. et al. The incidence and economic significance of ovine toxoplasmosis in Uruguay. Veterinary Parasitology, Amsterdam, n.1, v.81, p.85-88, 1999.

GARCÍA-VÁZQUEZ, Z.; ROSARIO-CRUZ, R.; SOLORZANOSALGADO, M. Prevalence of antibodies against Toxoplasma gondii in sheep and goats in three states of Mexico. Preventive Veterinary Medicine, Amsterdam, n.1, v.10, p.25-29, 1990.

GONDIM, L.F.P. et al. Serological survey of antibodies to Toxoplasma gondii in goats, sheep, cattle and water buffaloes in Bahia State, Brazil. Veterinary Parasitology, Amsterdam, n.3, v.82, p.273-276, 1999.

LANGONI, H. et al. Inquérito soroepidemiológico para a toxoplasmose em ovinos no Estado de São Paulo, Brasil. O Biológico, São Paulo, v.61, n.1, p.35-39, 1999.

LARSSON, C.E.; JAMRA, L.M.F.; GUIMARÃES, E.C. Prevalência da toxoplasmose ovina determinada pela reação de Sabin-Feldman em animais de Uruguaiana, RS, Brasil. Revista de Saúde Pública, São Paulo, n.4, v.14, p.582-588, 1980.
MACHADO, T.M.M.; LIMA, J.D. Freqüência de anticorpos anti-Toxoplasma gondii em caprinos criados sob diferentes formas de exploração no Estado de Minas Gerais. Arquivos Brasileiros de Medicina Veterinária e Zootecnia, Belo Horizonte, n.2, v.39, p.255-264, 1987

MAINAR, R.C. et al. Prevalence of agglutinating antibodies to Toxoplasma gondii in small ruminants of the Madri Region, Spain, and identification of factors influencing seropositivity by multivariate analysis. Veterinary Research Communications, Amsterdam, n.2, v.20, p.153-159, 1996.

MUNDAY, B.L.; MASON, R.W. Toxoplasmosis as a cause of perinatal death in goats. Australian Veterinary Journal, Artarmon, n.10, v.55, p.485-487, 1979.

OPEL, U. et al. A survey of the prevalence of Toxoplasma infection in goats in New Zealand and a comparison of the latex agglutination and indirect fluorescence tests. Veterinary Parasitology, Amsterdam, n.2, v.40, p.181186, 1991.

SPOSITO FILHA, E. et al. Toxoplasma gondii em ovinos: Isolamento do parasita a partir de diafragmas de animais procedentes do Estado do Rio Grande do Sul e abatidos em matadouros de São Paulo, para consumo humano. Revista Brasileira de Parasitologia Veterinária, São Paulo, n.2, v.1., p.118$119,1992$.

TENTER, A.M.; HECKEROTH, A.R.; WEISS, L.M. Toxoplasma gondii: from animals to humans. International Journal for Parasitology, Brisbane, n.12/13, v.30, p.12171258,2000 .

UNDERWOOD, W.J.; ROOK, J.S. Toxoplasmosis infection in sheep. The Compendium on Continued Education in Veterinary Practice, NewYork, n.8, v.14, p.1543-1549, 1992.

WALTNER-TOEWS, D.; MONDESIRE, R.; MENZIES, P. The seroprevalence of Toxoplasma gondii in Ontario sheep flocks. Canadian Veterinary Journal, Ottawa, n.12, v.32, p.734737,1991 